\title{
Long-chain $n$-3 PUFA supplementation decreases physical activity during class time in iron-deficient South African school children
}

\author{
Cornelius M. Smuts ${ }^{1}$, Jani Greeff ${ }^{1}$, Jane Kvalsvig ${ }^{2}$, Michael B. Zimmermann ${ }^{3}$ and \\ Jeannine Baumgartner ${ }^{1,3 *}$ \\ ${ }^{1}$ Centre of Excellence for Nutrition, North-West University, Potchefstroom Campus, Private Bag X6001, \\ Potchefstroom 2520, South Africa \\ ${ }^{2}$ Department of Psychology, University of KwaZulu-Natal, Durban, South Africa \\ ${ }^{3}$ Laboratory of Human Nutrition, Institute of Food, Nutrition and Health, ETH Zürich, Switzerland
}

(Submitted 21 May 2014 - Final revision received 19 August 2014 - Accepted 2 October 2014 - First published online 4 December 2014)

\begin{abstract}
Both Fe deficiency and poor $n$-3 fatty acid status have been associated with behavioural changes in children. In the present study, we investigated the effects of Fe and DHA + EPA supplementation, alone or in combination, on physical activity during school days and on teacher-rated behaviour in healthy Fe-deficient school children. In a $2 \times 2$ factorial design, children ( $n$ 98, 6-11 years) were randomly assigned to receive (1) Fe (50 mg) plus DHA (420 mg) + EPA ( $80 \mathrm{mg})$, (2) Fe plus placebo, (3) placebo plus DHA + EPA or (4) placebo plus placebo as oral supplements ( $4 \mathrm{~d} /$ week) for 8.5 months. Physical activity was measured during four school days at baseline and endpoint using accelerometers, and data were stratified into morning class time (08.00-10.29 hours), break time (10.30-11.00 hours) and after-break class time (11.01-12.00 hours) for analysis. Classroom behaviour was assessed at endpoint using Conners' Teacher Rating Scales. DHA + EPA supplementation decreased physical activity counts during morning class time, increased sedentary physical activity, and decreased light- and moderate-intensity physical activities. Consistently, DHA + EPA supplementation increased sedentary physical activity and decreased light-intensity physical activity during after-break class time. Even though there were no treatment effects found on teacher-rated behaviour, lower physical activity during morning class time was associated with lower levels of teacher-rated hyperactivity and oppositional behaviour at endpoint. Despite a positive association between Fe status and physical activity during break time at baseline, Fe supplementation did not affect physical activity during break time and class time. Our findings suggest that DHA + EPA supplementation may decrease physical activity levels during class time, and further indicate that accelerometry might be a useful tool to assess classroom behaviour in healthy children.
\end{abstract}

Key words: $\boldsymbol{n}$-3 Fatty acids: Iron: Physical activity: Behaviour: School children

Fe deficiency (ID) and inadequate intakes of $n$ - 3 fatty acids (FA) often coexist in child populations, particularly in developing countries. Fe and $n-3$ FA play important roles in brain development and function ${ }^{(1,2)}$, and both ID and low $n-3$ FA status have been associated with behavioural disorders, such as Attention-Deficit Hyperactivity Disorder (ADHD) and dyslexia, in children ${ }^{(3-5)}$. A great deal of evidence has shown that inadequate neuronal levels of the $n$ - 3 long-chain PUFA, DHA (22:6n-3) and EPA $(20: 5 n-3)$, as well as inadequate brain Fe stores, can affect the morphological development, physiology and chemistry of the brain ${ }^{(1,6-8)}$. Furthermore, we have previously shown in rats that a combined deficiency of Fe and $n-3$ FA resulted in greater deficits in monoaminergic neurotransmission than a deficiency in Fe or $n-3$ FA alone ${ }^{(9)}$.
Particularly, deficits in dopaminergic and serotonergic neurotransmission may be responsible for behavioural abnormalities during childhood ${ }^{(5,10)}$.

Even though several observational studies have shown that children with ADHD have low $n-3$ FA and Fe status ${ }^{(1,3,11)}$, the therapeutic effects of $n$ - 3 PUFA supplementation in children with ADHD are not conclusive ${ }^{(12)}$, and a recent systematic review has found that the same is true for Fe supplementation ${ }^{(3)}$. However, while the majority of studies investigating the effects of $n$-3 FA or Fe supplementation on behaviour have been performed in children with a diagnosed behavioural disorder ${ }^{(13-15)}$, such as ADHD or dyslexia, none or only a few studies have assessed the effects of Fe and $n-3$ FA supplementation, respectively, on behaviour in healthy school children ${ }^{(15-20)}$.

Abbreviations: ADHD, Attention-Deficit Hyperactivity Disorder; BAZ, BMI-for-age $z$-score; CTRS-R:S, Conners' Teacher Rating Scales - Revised: Short Form; FA, fatty acids; ID, Fe deficiency; TfR, transferrin receptor; ZnPP, Zn protoporphyrin.

*Corresponding author: J. Baumgartner, email jeannine.baumgartner@gmail.com 
Behavioural abnormalities are often characterised by overactivity $^{(21)}$. In several rat studies, deficiency in dietary $n$-3 FA resulted in elevated locomotor activity ${ }^{(22,23)}$. In a recent study using a rat model of ADHD, the provision of an $n-3$ FA-enriched diet for 6 weeks significantly reduced motor activity when compared with the administration of an n-3 FA-deficient diet, which - according to the authors - could be interpreted as an improvement in hyperactivity ${ }^{(24)}$. However, to our knowledge, only one study has investigated the potential relationship between $n$ - 3 FA status and physical activity in healthy school children. A recent cross-sectional study conducted in 8- to 11-year-old Danish children without diagnosed ADHD has found a negative association between DHA status and physical activity, particularly of light intensity ${ }^{(25)}$.

In contrast to $n$ - 3 FA deficiency, ID and ID anaemia have been associated with reduced voluntary motor/physical activity in animals and humans ${ }^{(26-30)}$; however, only some studies have found an increase in activity after correction of Fe status ${ }^{(31)}$. The majority of these studies have been performed in infants. Nonetheless, it has been suggested that being physically active plays an important role in learning from the environment and in cognitive development during infancy $^{(32)}$, and the same could be true for school children.

However, it is logical to presume that increased motor activity during class time may reflect on behaviours such as restlessness, squirming, inability to remain still and distracting others - all of which are ADHD-related behaviours - which could potentially be detected by using an accelerometer. To our knowledge, however, none of the studies conducted in school children without diagnosed behavioural disorders has used accelerometers to assess physical activity in a behavioural context during school time.

Therefore, the aim of the present randomised, double-blind, placebo-controlled trial was to investigate the effects of $\mathrm{Fe}$ and DHA + EPA supplementation, alone or in combination, on physical activity during morning class time, break time and after-break class time, and on teacher ratings of ADHDrelated behaviour in Fe-deficient, non-ADHD-diagnosed South African school children. Furthermore, we explored whether physical activity levels during class time were associated with teacher-rated behaviour.

\section{Experimental methods}

\section{Participants and study design}

The present study was nested within a previously reported randomised, placebo-controlled, double-blind, $2 \times 2$ factorial trial that investigated the effects of Fe and DHA + EPA supplementation, alone or in combination, on cognition in 321 school children with poor Fe and $n$ - 3 FA status ${ }^{(33)}$. In brief, this trial was conducted between November 2009 and November 2010 at four primary schools serving low-income rural villages in the province of KwaZulu-Natal in eastern South Africa ${ }^{(33)}$. Inclusion criteria for the study were as follows: (1) 6-11 years of age; (2) $\mathrm{Hb}$ concentration $>80 \mathrm{~g} / \mathrm{l}$; (3) ID, which was defined as either a serum ferritin concentration
$<20 \mu \mathrm{g} / 1$, a $\mathrm{Zn}$ protoporphyrin (ZnPP) concentration $>70 \mu \mathrm{mol} / \mathrm{mol}$ haem in washed erythrocytes, or a serum transferrin receptor (TfR) concentration $>8.3 \mathrm{mg} / 1$; (4) apparently healthy, with no chronic illness; (5) no consumption of Fe- or $n$-3 FA-containing supplements. For the present study, all participating children from the largest of the four primary schools ( $n$ 98; from grades 2 to 4 ) were selected. This was the only school with a playing area of approximately $30 \times 50 \mathrm{~m}$, while the other three schools did not contain any playing space and were therefore excluded in order to minimise potential variability in physical activity caused by environmental factors. The present study was conducted according to the guidelines laid down in the Declaration of Helsinki, and all procedures involving human subjects were approved by the ethical committees of the North-West University and Swiss Federal Institute of Technology (ETH). Written informed consent from the parents or guardians and verbal assent from the children were obtained. The trial was registered at ClinicalTrials.gov as NCT01092377.

\section{Randomisation and intervention}

Details on randomisation, blinding and intervention have been described previously ${ }^{(33)}$. In brief, children were randomly allocated to receive (1) Fe plus DHA + EPA, (2) placebo plus DHA + EPA, (3) Fe plus placebo or (4) placebo plus placebo as oral supplements. The intervention began at the beginning of the school year and continued throughout the whole school year ( 8.5 months). The Fesupplemented groups received one oral tablet of $50 \mathrm{mg} \mathrm{Fe}$ as iron sulphate (Lomapharm; Paul Lohmann $\mathrm{GmbH}$ ) on $4 \mathrm{~d}$ /week during school days. The respective non-Fesupplemented (placebo) groups received the same regimen of placebo tablets (Lomapharm; Paul Lohmann GmbH) that were identical in appearance to the Fe tablets. The DHA + EPA-supplemented groups received two oral capsules of fish oil that contained a total of $420 \mathrm{mg}$ DHA and $80 \mathrm{mg}$ EPA (Burgerstein AG) on $4 \mathrm{~d} /$ week during school days. The respective non-DHA + EPA-supplemented (placebo) groups received the same regimen of placebo capsules that contained medium-chain TAG (RP Scherer GmbH) and were identical in appearance and total fat content to the DHA + EPA capsules. The Fe or respective placebo tablets were administered under the supervision of a trained fieldworker in the morning when the children arrived at school (before 08.00 hours) together with a fruit-flavoured beverage providing approximately $10 \mathrm{mg}$ vitamin $\mathrm{C}$ per serving. The DHA + EPA or respective placebo capsules were provided $2.5 \mathrm{~h}$ later during midmorning break. In total, the supplements were provided for $105 \mathrm{~d}$ over a period of 8.5 months. The mean total Fe intake during the $105 \mathrm{~d}$ trial was $4.8 \mathrm{~g}$ in the groups that received the Fe tablets and corresponded to approximately $18 \mathrm{mg} \mathrm{Fe} / \mathrm{d}$ across the entire study period (including weekends and holidays). The mean total DHA and EPA intakes were 41.2 and $7.8 \mathrm{~g}$, respectively, in the groups that received the DHA + EPA capsules and corresponded to approximately $155 \mathrm{mg}$ DHA and $29 \mathrm{mg} \mathrm{EPA} / \mathrm{d}$ across the entire study period.

which was defined as either a serum feritin concentration 


\section{Anthropometric measures}

Body weight and height were measured as described previously ${ }^{(33)}$. The age- and sex-specific height-for-age $z$-score, the weight-for-age $z$-score and the BMI-for-age $z$-score (BAZ) were calculated by using the 2007 WHO Growth Standards for children aged 5-19 years with the software WHO Anthro Plus for personal computers (version 1.0.3, 2010). Stunting was defined as a height-for-age $z$-score $<-2$, and mild stunting was defined as a height-for-age $z$-score $<-1$ and $\geq-2$. Children with a weight-for-age $z$-score $<-2$ were classified as underweight, those with a BAZ $>1$ and $<2$ were classified as overweight, and those with a $\mathrm{BAZ} \geq 2$ were classified as obese.

\section{Biochemical indicators}

Venous blood samples $(10 \mathrm{ml})$ were drawn into EDTA-coated and trace element-free evacuated tubes (Becton Dickinson) at baseline and endpoint. Hb concentrations in whole blood, serum ferritin, C-reactive protein and TfR concentrations in serum and ZnPP concentrations in washed erythrocytes were measured as described previously ${ }^{(33)}$. Analysis of total phospholipid FA in washed erythrocytes has also been described previously ${ }^{(33)}$.

\section{Physical activity}

Physical activity was measured during school days by using forty-eight Actical activity monitors (Mini Mitter; Philips Respironics), which are small $(2.8 \times 2.7 \times 1.0 \mathrm{~cm}, 17 \mathrm{~g})$ electronic devices that house an omni-directional accelerometer. The Actical accelerometer has previously been demonstrated to be a valid measure of activity in children for populationbased studies ${ }^{(34)}$. Children were randomised to wear the accelerometer on four different school days (completion within 8-12 school days) at baseline (February 2010) and at endpoint (October 2010). Four days (replicates) per subject and time point (baseline/endpoint) were chosen to obtain a more precise measure of physical activity, considering potential day-to-day variation in activity. The accelerometers were randomised between subjects (none of the children wore the same Actical accelerometer twice). In the morning when the children arrived at school (before 08.00 hours), the accelerometers were securely strapped around the children's waist with an elastic belt and placed over the right hip. After school before the children went home (before 13.00 hours), the accelerometers were removed. The accelerometers were programmed to record physical activity from 08.00 to 12.00 hours in $60 \mathrm{~s}$ epochs. The teachers were asked to inform the investigators in advance about any planned special events/ activities, such as sports and examination days. Such days were excluded from the analysis. Furthermore, the trained researcher who was responsible for executing the activity measurements stayed at the school during the entire school day on each day of data collection in order to observe potential extraordinary events that could have influenced physical activity, such as accidents (e.g. serious car accident on the school ground), unannounced sports activities during class time, etc. In case of such an event, data from the affected children were excluded from the analysis. The researcher present at the school also observed whether the accelerometers were worn for a shorter time period (e.g. when a child arrived late or left school earlier). Activity data were uploaded from the monitor to the computer after each day by using the accelerometer device software (Actical version 2.1.2; Philips Respironics). Data from school days were divided into three different time periods: morning class time (08.00-10.29 hours); break time (10.30-11.00 hours); after-break class time (11.0112.00 hours). The decision to analyse physical activity counts and intensity levels for the morning class time and after-break class time separately was made before the start of data collection. The reasons were as follows: (1) we observed during our pre-visits that the morning class time was more academically focused than the after-break class time; (2) the children received a meal during break time that could affect activity levels during after-break class time; (3) it has been well documented that behavioural and physiological variables of children change throughout the school day ${ }^{(35)}$. For each time period, mean physical activity counts per min were calculated. Furthermore, percentage of time spent in sedentary, light-, moderate- and vigorous-intensity physical activities was defined as a percentage of total minutes spent on physical activity of $<48,48-2031,2032-2872$ and $>2872$ counts/min, respectively. These physical activity intensity cut-offs for children using the Actical accelerometer were proposed by Evenson et al. ${ }^{(36)}$ and confirmed more recently by Colley \& Tremblay ${ }^{(37)}$.

\section{Conners' Teacher Rating Scales}

To determine whether physical activity counts and intensity levels of a child during class time are associated with the teacher's perception of the child's behaviour, we applied the Conners' Teacher Rating Scales - Revised: Short Form (CTRS-R:S). The Conners' Teacher Rating Scales is a commonly used rating scale applied for the assessment of classroom behaviour problems related to $\mathrm{ADHD}^{(38)}$. The general purpose of the scale is to provide information at the screening level to assist clinicians and researchers in understanding several important domains of the child's behaviour ${ }^{(39)}$. The CTRS-R:S is a questionnaire for teachers that contains twenty-eight items concerning the behaviour of a child. Each item is scored using a Likert scale ranging from 0 to 4 ( 0 being 'not true at all' and 4 being 'very much true'). Higher scores indicate greater severity of symptoms. The CTRS-R:S consists of three factor-derived subscales (oppositional, cognitive problems/inattention and hyperactivity), as well as of the ADHD Index that is aligned with the Diagnostic and Statistical Manual of Mental Disorders, fourth edition criteria for $\mathrm{ADHD}^{(40)}$. A trained, local fieldworker was assigned to interview the teachers, asking them the questions appearing on the CTRS-R:S for each child included in the study. This was done in an effort to improve the quality of the data. We initially planned to apply the CTRS-R:S at baseline and endpoint. However, we decided not to perform a baseline 
assessment since the study started at the beginning of the school year and the teachers felt that they did not know their learners ( $n$ 30-40 per class) well enough yet to rate their behaviour.

\section{Statistical analyses}

Statistical analyses were performed using IBM SPSS Statistics (version 21; IBM Company). All data were checked for normal distribution. Skewed variables were transformed before data analysis. Estimated intervention effects of $\mathrm{Fe}$ ( $\mathrm{Fe}$ $v$. placebo) and of DHA + EPA (DHA + EPA $v$. placebo) and their interactions were analysed by using two-factor ANCOVA on the endpoint measurement by using the respective baseline values (except for CTRS-R:S data), sex, age and compliance (only for biochemical variables) as individual covariates. When a statistically significant interaction was found, one-way ANOVA was performed to compare the treatment groups in order to interpret the nature of the interaction. Multiple linear regression analyses were performed to determine the associations between physical activity and biochemical indicators of $\mathrm{Fe}$ and $n-3 \mathrm{FA}$ status at baseline, adjusting for age and sex. Multiple linear regression analyses were also performed to determine the associations between physical activity and subscale scores of the CTRS-R:S at endpoint, adjusting for age, sex and BAZ. Paired $t$ tests were used to determine within-group differences in physical activity between baseline and endpoint. Independent $t$ tests were used to investigate the differences in physical activity between girls and boys. $P$ values $<0.05$ were considered significant.

\section{Results}

\section{Subjects}

Of the ninety-eight children selected to participate in the present study, eighty-nine children completed the study, resulting in a dropout rate of $9 \%$. Only nine children withdrew from the study because they did not like taking the supplements ( $n$ 4), complained about side effects (headache; $n$ ), left school ( $n$ 1), or withdrew for no reason $(n 3)$. The baseline characteristics of the children in total and by supplementation group are shown in Table 1 . There were no differences observed in any baseline characteristics between the supplementation groups. The mean adherence to treatment (observed capsules and tablets swallowed during the $105 \mathrm{~d}$ trial) was $90 \%$ and did not differ between the treatment groups.

\section{Baseline associations}

At baseline, $\mathrm{Hb}$ concentrations were positively associated with physical activity counts during break time ( $P=0 \cdot 004$; Table 2$)$. The Fe status markers TfR and ZnPP were both negatively associated with physical activity counts during break time at baseline (TfR, $P=0 \cdot 006$; ZnPP, $P=0 \cdot 006$ ). Higher TfR concentrations - indicative of worse Fe status - were associated with more time spent in sedentary physical activity $(P=0 \cdot 019)$ and less time spent in moderate-intensity $(P=0.020)$ and vigorous-intensity $(P=0.023)$ physical activities during break time. Similarly, higher ZnPP concentrations - indicative of worse Fe status - were associated with less time spent in moderate-intensity physical activity during break time $(P=0 \cdot 015)$. We also found a negative association between the relative content of ARA in the total phospholipid fraction of erythrocyte membranes and the percentage of time spent in moderate-intensity physical activity during break time at baseline (Table 2). Furthermore, a higher $n-6: n-3$ ratio in erythrocyte membranes was associated with lower physical activity counts $(B=-29 \cdot 6,95 \% \mathrm{CI}-48 \cdot 2,-5 \cdot 1)$ and less time spent in vigorous-intensity physical activity $(B=-0 \cdot 3$, $95 \%$ CI $-0 \cdot 6,-0 \cdot 1)$ during after-break class time at baseline (data not shown). There were no significant associations observed between BAZ and physical activity (counts and levels) during any of the three time periods at baseline. Also, there was no intervention effect on BAZ. Therefore, we decided not to include BMI as a covariate in the statistical analyses.

\section{Biochemical indicators}

Concentration of Fe status indicators and the relative content of selected $n-3$ and n-6 long-chain-PUFA of erythrocyte membranes at baseline and after the 8.5-month intervention by supplementation group are shown in online supplementary Table S1. Fe supplementation improved Fe status and $\mathrm{Hb}$ concentrations, indicated by a significant treatment effect of Fe on all Fe indices (serum ferritin, $P<0.001$; TfR, $P<0.001$; body Fe, $P<0.001 ; \mathrm{ZnPP}, P=0.004)$ and on $\mathrm{Hb}$ concentrations $(P=0 \cdot 026)$. DHA + EPA supplementation significantly increased the relative content of EPA $(P<0.001)$ and DHA $(P<0.001)$ in the total phospholipid fraction of erythrocyte membranes, and decreased the relative content of ARA $(P<0.001)$ and the $n-6: n-3$ FA ratio $(P<0 \cdot 001)$. Furthermore, there was also a significant treatment effect of $\mathrm{Fe}$ for decreased relative content of ARA $(P<0 \cdot 014)$ and a significant $\mathrm{Fe} \times \mathrm{DHA}+\mathrm{EPA}$ interaction $(P=0 \cdot 020)$. Compared with the placebo plus placebo group, the relative content of ARA at endpoint was lower in the placebo plus DHA + EPA $(P=0.027)$ and the Fe plus DHA + EPA $(P=0.038)$ groups, while the $\mathrm{Fe}$ plus placebo group did not differ from any of the groups.

\section{Physical activity}

No significant intervention effects were found on physical activity counts and intensity levels during break time (Table 3). All the four groups had significantly lower activity counts and spent less time in high-intensity physical activity levels at endpoint compared with baseline. At endpoint, time spent in sedentary physical activity during break time was higher $(B=2 \cdot 89, \quad P=0.016)$, while time spent in light-intensity $(B=-2 \cdot 24, P=0.030)$ and vigorous-intensity $(B=-0.660$, $P=0.047)$ physical activities was lower with increasing age.

DHA + EPA supplementation significantly decreased physical activity counts per min during morning class time $(P=0.023$; Table 4). DHA + EPA supplementation increased the percentage of time spent in sedentary physical activity during morning class time $(P=0.033)$ while decreasing the 
Table 1. Baseline characteristics of the study participants

(Number of participants and percentages; mean values and standard deviations; medians, minimum and maximum values) $\ddagger$

\begin{tabular}{|c|c|c|c|c|c|c|c|c|c|c|}
\hline & & & \multicolumn{8}{|c|}{ Supplementation group* } \\
\hline & \multicolumn{2}{|c|}{$\begin{array}{c}\text { All } \\
\text { participants } \\
(n 98)\end{array}$} & \multicolumn{2}{|c|}{$\begin{array}{l}\text { Fe plus } \\
\text { placebo } \\
(n 24)\end{array}$} & \multicolumn{2}{|c|}{$\begin{array}{c}\text { Placebo plus } \\
\text { DHA + EPA } \\
(n 25)\end{array}$} & \multicolumn{2}{|c|}{$\begin{array}{c}\text { Fe plus } \\
\text { DHA + EPA } \\
(n 24)\end{array}$} & \multicolumn{2}{|c|}{$\begin{array}{l}\text { Placebo plus } \\
\text { placebo } \\
(n 25)\end{array}$} \\
\hline & $n$ & $\%$ & $n$ & $\%$ & $n$ & $\%$ & $n$ & $\%$ & $n$ & $\%$ \\
\hline \multicolumn{11}{|l|}{ Age (years) } \\
\hline Mean & \multicolumn{2}{|c|}{$8 \cdot 4$} & \multicolumn{2}{|c|}{$8 \cdot 4$} & \multicolumn{2}{|c|}{$8 \cdot 3$} & \multicolumn{2}{|c|}{$8 \cdot 3$} & \multicolumn{2}{|c|}{$8 \cdot 6$} \\
\hline SD & \multirow{2}{*}{\multicolumn{2}{|c|}{0.102}} & \multicolumn{2}{|c|}{$1 \cdot 16$} & \multicolumn{2}{|c|}{0.82} & \multirow{2}{*}{\multicolumn{2}{|c|}{1.02}} & \multirow{2}{*}{\multicolumn{2}{|c|}{1.02}} \\
\hline Grade & & & & & & & & & & \\
\hline Grade 2 & 28 & 28.6 & 7 & $29 \cdot 2$ & 7 & $28 \cdot 0$ & 8 & 33.3 & 6 & 24.0 \\
\hline Grade 3 & 31 & 31.6 & 7 & 29.2 & 8 & $32 \cdot 0$ & 7 & 29.2 & 9 & 36.0 \\
\hline Grade 4 & 39 & $39 \cdot 8$ & 10 & $41 \cdot 7$ & 10 & $40 \cdot 0$ & 9 & 37.5 & 10 & $40 \cdot 0$ \\
\hline Sex & & & & & & & & & & \\
\hline Boys & 49 & $50 \cdot 0$ & 15 & $62 \cdot 5$ & 13 & $52 \cdot 0$ & 11 & $45 \cdot 8$ & 10 & 40.0 \\
\hline Girls & 49 & $50 \cdot 0$ & 9 & 37.5 & 12 & $48 \cdot 0$ & 13 & $54 \cdot 2$ & 15 & $60 \cdot 0$ \\
\hline Anthropometric indices & & & & & & & & & & \\
\hline Stunting $(\mathrm{HAZ}<-2 \mathrm{SD})$ & 6 & $6 \cdot 1$ & 4 & $16 \cdot 7$ & 1 & 4.0 & 1 & $4 \cdot 2$ & 0 & 0 \\
\hline Mildly stunted $(\mathrm{HAZ}<-1 \mathrm{SD} \geq-2 \mathrm{SD})$ & 28 & $28 \cdot 6$ & 7 & $29 \cdot 2$ & 7 & $28 \cdot 0$ & 4 & $16 \cdot 7$ & 10 & $40 \cdot 0$ \\
\hline Underweight $(\mathrm{WAZ}<-2 \mathrm{SD})$ & 1 & $1 \cdot 1$ & 0 & 0 & 0 & 0 & 1 & $4 \cdot 2$ & 0 & 0 \\
\hline Overweight (BAZ > $1 \mathrm{SD}<2 \mathrm{SD})$ & 24 & 24.7 & 5 & $21 \cdot 7$ & 6 & $24 \cdot 0$ & 8 & $33 \cdot 3$ & 5 & $20 \cdot 0$ \\
\hline Obese $(\mathrm{BAZ} \geq 2 \mathrm{SD})$ & 7 & $7 \cdot 2$ & 2 & $8 \cdot 7$ & 0 & 0 & 1 & $4 \cdot 2$ & 4 & $16 \cdot 0$ \\
\hline Fe and anaemia status indicators & & & & & & & & & & \\
\hline $\mathrm{Hb}(\mathrm{g} / \mathrm{l})$ & & & & & & & & & & \\
\hline Mean & & & & & & & & & & \\
\hline SD & & & & & & & & & & \\
\hline$S F(\mu g / l) \dagger$ & & & & & & & & & & \\
\hline Median & & & & & & & & & & \\
\hline Minimum to maximum & & 3.5 & & 33.5 & & 50.8 & & $51 \cdot 1$ & & 58.2 \\
\hline $\operatorname{TfR}(\mathrm{mg} / \mathrm{l})$ & & & & & & & & & & \\
\hline Median & & & & & & & & & & \\
\hline Minimum to maximum & & 1.8 & & 10.2 & & & & 8.8 & & 1.8 \\
\hline Body Fe $(\mathrm{mg} / \mathrm{kg}) \S$ & & & & & & & & & & \\
\hline Mean & & & & & & & & & & \\
\hline SD & & & & & & & & & & \\
\hline ZnPP $(\mu \mathrm{mol} / \mathrm{mol}$ haem $)$ & & & & & & & & & & \\
\hline Median & & & & & & & & & & \\
\hline Minimum to maximum & 39. & $15 \cdot 0$ & 39 . & $127 \cdot 0$ & 44. & $215 \cdot 0$ & & $96 \cdot 0$ & & 171.0 \\
\hline Erythrocyte fatty acids & & & & & & & & & & \\
\hline EPA (\% of total fatty acids) & & & & & & & & & & \\
\hline Median & & & & & & & & & & \\
\hline Minimum to maximum & & 0.34 & & 0.28 & & 0.32 & & 0.34 & & 0.31 \\
\hline DHA (\% of total fatty acids) & & & & & & & & & & \\
\hline Mean & & & & & & & & & & \\
\hline SD & & & & & & & & & & \\
\hline ARA ( $\%$ of total fatty acids) & & & & & & & & & & \\
\hline Median & & & & & & & & & & \\
\hline Minimum to maximum & & $18 \cdot 1$ & & $17 \cdot 4$ & & $18 \cdot 1$ & & $17 \cdot 6$ & & $17 \cdot 0$ \\
\hline Deficiencies & & & & & & & & & & \\
\hline Anaemia $(<115 \mathrm{~g} \mathrm{Hb} / \mathrm{l})$ & 18 & $18 \cdot 8$ & 6 & $26 \cdot 1$ & 3 & $12 \cdot 0$ & 4 & $16 \cdot 7$ & 5 & $20 \cdot 8$ \\
\hline Fe deficiency based on SF $(<15 \mu \mathrm{g} / \mathrm{l})$ & 19 & $22 \cdot 6$ & 3 & $16 \cdot 7$ & 5 & $26 \cdot 3$ & 5 & $20 \cdot 8$ & 6 & 26.1 \\
\hline Fe deficiency based on TfR $(>8.3 \mathrm{mg} / \mathrm{l})$ & 12 & $12 \cdot 2$ & 3 & 12.5 & 1 & 4.0 & 3 & 12.5 & 5 & 20.0 \\
\hline Fe deficiency based on ZnPP ( $>70 \mu \mathrm{mol} / \mathrm{mol}$ haem $)$ & 60 & 94.9 & 17 & $70 \cdot 8$ & 15 & $68 \cdot 2$ & 12 & $50 \cdot 0$ & 16 & 69.6 \\
\hline Shortage of body $\mathrm{Fe}$ (negative values) & 8 & 9.5 & 2 & $11 \cdot 1$ & 2 & $10 \cdot 5$ & 2 & $8 \cdot 3$ & 2 & 8.7 \\
\hline Fe-deficiency anaemia $(<115 \mathrm{~g} \mathrm{Hb} / \mathrm{l}$ and $<15 \mu \mathrm{g} \mathrm{SF} / \mathrm{l})$ & 7 & 8.5 & 2 & $11 \cdot 8$ & 2 & 10.5 & 2 & $8 \cdot 3$ & 1 & 4.5 \\
\hline Acute-phase protein & & & & & & & & & & \\
\hline C-reactive protein $>5 \mathrm{mg} / \mathrm{l}$ & 9 & $9 \cdot 6$ & 4 & $18 \cdot 2$ & 5 & $20 \cdot 8$ & 0 & 0 & 0 & 0 \\
\hline
\end{tabular}

HAZ, height-for-age $z$-score, WAZ, weight-for-age $z$-score; BAZ, BMI-for-age $z$-score; SF, serum ferritin; TfR, transferrin receptor; ZnPP, Zn protoporphyrin; ARA, arachidonic acid.

${ }^{*}$ Potential baseline differences between the intervention groups were investigated using one-way ANOVA for continuous variables or $\chi^{2}$ test with Bonferroni correction for categorical variables.

†SF values of all subjects with a C-reactive protein concentration $>5 \mathrm{mg} / \mathrm{l}$ were excluded.

$\ddagger$ Data were log-transformed to perform ANOVA.

$\S$ Total body Fe concentration was calculated according to the method proposed by Cook et al. ${ }^{(46)}$. 
time spent in light-intensity $(P=0.024)$ and moderate-intensity $(P=0.009)$ physical activities. Time spent in vigorous-intensity physical activity was not influenced by treatment, but was lower with increasing age $(B=-0 \cdot 129, P=0 \cdot 041)$.

No significant intervention effects were found on physical activity counts during after-break class time (Table 4). All the four groups had significantly higher activity counts and spent more time in higher activity levels at endpoint compared with baseline. However, DHA + EPA supplementation significantly increased time spent in sedentary physical activity ( $P=0.025$ ) during after-break class time at endpoint while decreasing the time spent in light-intensity physical activity $(P=0.021)$ (Table 4). Furthermore, time spent in moderateand vigorous-intensity physical activities during after-break class time at endpoint was significantly higher in boys than in girls (moderate, $B=1 \cdot 29, P=0.049$; vigorous, $B=2 \cdot 70$, $P=0 \cdot 001)$, with no significant sex $\times$ treatment interactions.

\section{Classroom behaviour and associations with physical activity}

No significant intervention effects were found on any of the subscale scores of the CTRS-R:S or on the ADHD Index (Table 5). However, mean physical activity counts during morning class time at endpoint were positively associated with the oppositional $(\beta=0.375, P<0.001)$ and hyperactivity ( $\beta=0 \cdot 470, P<0 \cdot 001$ ) (Fig. 1) subscale scores of the CTRS-R:S, and with the ADHD Index $(\beta=0 \cdot 400, P<0 \cdot 001)$ (Table 6). Furthermore, time spent in sedentary physical activity during morning class time at endpoint was negatively associated with oppositional, hyperactivity and ADHD Index scores. In contrast, light-, moderate- and vigorous-intensity physical activities during morning class time were positively associated with oppositional, hyperactivity and ADHD Index scores (only the association between moderate-intensity physical activity and the ADHD Index was not significant, $P=0.096$ ).

\section{Discussion}

To our knowledge, this is the first randomised, double-blind, placebo-controlled trial investigating the effects of Fe and DHA + EPA supplementation, alone or in combination, on physical activity and ADHD-related behaviour in Fe-deficient, non-ADHD-diagnosed school children.

Our main findings were that DHA + EPA supplementation decreased physical activity counts during morning class time; children who received DHA + EPA supplements spent more time in sedentary physical activity and less time in light- and moderate-intensity physical activities. Consistently, children who received DHA + EPA supplements spent more time in sedentary physical activity at the expense of light-intensity physical activity during after-break class time. These findings are in accordance with the observations made in a recent cross-sectional study showing that DHA status in Danish school children was negatively associated with physical activity counts and time spent in light-intensity physical activity $^{(25)}$. However, in that study, physical activity was assessed during seven consecutive days and not specifically 
Table 3. Effects of the intervention with iron and DHA + EPA, alone or in combination, on physical activity counts and intensity levels during break time (Mean values and standard deviations; $B$ coefficients and $95 \%$ confidence intervals)

\begin{tabular}{|c|c|c|c|c|c|c|c|c|c|c|c|c|c|}
\hline & \multicolumn{8}{|c|}{ Supplementation group } & \multicolumn{5}{|c|}{ Estimated intervention effect ${ }^{*}$} \\
\hline & \multicolumn{2}{|c|}{$\begin{array}{l}\text { Fe plus placebo } \\
\quad(n 23-24)\end{array}$} & \multicolumn{2}{|c|}{$\begin{array}{c}\text { Placebo plus } \\
\text { DHA + EPA } \\
(n 24-25)\end{array}$} & \multicolumn{2}{|c|}{$\begin{array}{l}\text { Fe plus DHA + } \\
\text { EPA }(n 21-24)\end{array}$} & \multicolumn{2}{|c|}{$\begin{array}{l}\text { Placebo plus } \\
\text { placebo } \\
(n 21-25)\end{array}$} & \multicolumn{2}{|r|}{$\mathrm{Fe}$} & \multicolumn{2}{|c|}{$\mathrm{DHA}+\mathrm{EPA}$} & \multirow{2}{*}{$\begin{array}{c}\mathrm{Fe} \times \\
\mathrm{DHA}+\mathrm{EPA} \\
P\end{array}$} \\
\hline & Mean & SD & Mean & SD & Mean & SD & Mean & SD & $B$ & $95 \% \mathrm{Cl}$ & $B$ & $95 \% \mathrm{Cl}$ & \\
\hline \multicolumn{14}{|c|}{ Physical activity (counts/min) } \\
\hline Baseline & 817.5 & $245 \cdot 3$ & $797 \cdot 1$ & $217 \cdot 8$ & $847 \cdot 2$ & 287.5 & 794.0 & 346.9 & $-85 \cdot 6$ & $-201 \cdot 9,30 \cdot 7$ & $-19 \cdot 6$ & $-135 \cdot 7,96 \cdot 5$ & 0.590 \\
\hline Endpoint & 496.9 & 148.9 & 564.7 & 244.4 & $520 \cdot 6$ & $209 \cdot 8$ & $568 \cdot 7$ & $190 \cdot 0$ & & & & & \\
\hline \multicolumn{14}{|c|}{$\begin{array}{l}\text { Percentage of time spent in } \\
\text { sedentary physical activity }\end{array}$} \\
\hline Baseline & 25.5 & 7.97 & $25 \cdot 0$ & $11 \cdot 3$ & $25 \cdot 3$ & $11 \cdot 1$ & $24 \cdot 3$ & $11 \cdot 3$ & 4.7 & $-1 \cdot 8,11 \cdot 1$ & $2 \cdot 7$ & $-3 \cdot 6,9 \cdot 1$ & $0.278 \dagger$ \\
\hline Endpoint & 44.4 & $7 \cdot 71$ & $41 \cdot 2$ & $12 \cdot 6$ & 41.9 & 11.6 & $39 \cdot 2$ & $11 \cdot 3$ & & & & & \\
\hline \multicolumn{14}{|c|}{$\begin{array}{l}\text { Percentage of time spent in } \\
\text { light-intensity physical activity }\end{array}$} \\
\hline Baseline & $62 \cdot 2$ & 8.81 & $63 \cdot 4$ & 9.07 & 61.9 & $10 \cdot 7$ & $64 \cdot 2$ & $11 \cdot 1$ & $-3 \cdot 6$ & $-9 \cdot 2,2 \cdot 0$ & -1.9 & $-7.5,3.6$ & $0.282 \dagger$ \\
\hline Endpoint & 48.4 & $7 \cdot 21$ & $50 \cdot 9$ & $9 \cdot 70$ & $52 \cdot 0$ & $11 \cdot 0$ & $52 \cdot 7$ & $10 \cdot 0$ & & & & & \\
\hline \multicolumn{14}{|c|}{$\begin{array}{l}\text { Percentage of time spent in } \\
\text { moderate-intensity physical activity }\end{array}$} \\
\hline Baseline & 6.80 & 3.95 & 5.50 & 2.71 & 5.74 & 2.72 & 5.48 & $4 \cdot 14$ & -0.3 & $-1 \cdot 7,1 \cdot 2$ & -0.04 & $-1.4,1.4$ & $0.893 \ddagger$ \\
\hline Endpoint & $4 \cdot 13$ & 2.96 & 4.04 & $2 \cdot 87$ & 3.51 & 1.65 & 4.03 & 2.07 & & & & & \\
\hline \multicolumn{14}{|c|}{$\begin{array}{l}\text { Percentage of time spent in } \\
\text { vigorous-intensity physical activity }\end{array}$} \\
\hline Baseline & 5.54 & 3.93 & 6.06 & 3.96 & $6 \cdot 22$ & 4.09 & $5 \cdot 19$ & 3.45 & -1.0 & $-2 \cdot 8,0 \cdot 8$ & -0.9 & $-2 \cdot 7,1 \cdot 0$ & 0.957 \\
\hline Endpoint & $3 \cdot 11$ & 2.41 & 3.79 & $3 \cdot 76$ & $2 \cdot 65$ & 1.80 & $4 \cdot 14$ & 3.56 & & & & & \\
\hline
\end{tabular}

*Intervention effects were estimated by using ANCOVA, adjusted for the respective baseline values, sex and age.

$\dagger$ Age was a significant predictor $(P<0.05)$. 
Table 4. Effects of the intervention with iron and DHA + EPA, alone or in combination, on physical activity counts and intensity levels during morning class time and after-break class time (Mean values and standard deviations; $B$ coefficients and $95 \%$ confidence intervals)

\begin{tabular}{|c|c|c|c|c|c|c|c|c|c|c|c|c|c|}
\hline & \multicolumn{8}{|c|}{ Supplementation group } & \multicolumn{5}{|c|}{ Estimated intervention effect ${ }^{*}$} \\
\hline & \multicolumn{2}{|c|}{$\begin{array}{l}\text { Fe plus } \\
\text { placebo } \\
(n 23-24)\end{array}$} & \multicolumn{2}{|c|}{$\begin{array}{c}\text { Placebo plus } \\
\text { DHA + EPA } \\
(n 24-25)\end{array}$} & \multicolumn{2}{|c|}{$\begin{array}{l}\text { Fe plus DHA + } \\
\text { EPA }(n 21-24)\end{array}$} & \multicolumn{2}{|c|}{$\begin{array}{l}\text { Placebo plus } \\
\text { placebo } \\
(n 21-25)\end{array}$} & \multicolumn{2}{|r|}{$\mathrm{Fe}$} & \multicolumn{2}{|c|}{$\mathrm{DHA}+\mathrm{EPA}$} & \multirow{2}{*}{$\begin{array}{c}\mathrm{Fe} \times \\
\mathrm{DHA}+\mathrm{EPA} \\
P\end{array}$} \\
\hline & Mean & SD & Mean & SD & Mean & SD & Mean & SD & $B$ & $95 \% \mathrm{Cl}$ & $B$ & $95 \% \mathrm{Cl}$ & \\
\hline \multicolumn{14}{|c|}{ Morning class time $(08.00-10.29$ hours) } \\
\hline \multicolumn{14}{|c|}{ Physical activity (counts/min) } \\
\hline Baseline & $102 \cdot 2$ & $59 \cdot 0$ & 133.5 & $75 \cdot 8$ & $110 \cdot 6$ & $74 \cdot 7$ & $112 \cdot 9$ & $68 \cdot 7$ & -18.8 & $-53.4,15.9$ & $-40 \cdot 3$ & $-75 \cdot 0,-5 \cdot 6$ & 0.223 \\
\hline Endpoint & 119.7 & 44.4 & $105 \cdot 0$ & 44.7 & $108 \cdot 1$ & $67 \cdot 2$ & $135 \cdot 3$ & $77 \cdot 2$ & & & & & \\
\hline \multicolumn{14}{|c|}{$\begin{array}{l}\text { Percentage of time spent in } \\
\text { sedentary physical activity }\end{array}$} \\
\hline Baseline & $78 \cdot 0$ & $9 \cdot 0$ & $74 \cdot 7$ & 8.6 & $76 \cdot 1$ & $10 \cdot 4$ & $76 \cdot 6$ & $12 \cdot 7$ & 3.0 & $-1.9,7.9$ & $5 \cdot 3$ & $0.4,10 \cdot 2$ & 0.675 \\
\hline Endpoint & 73.9 & $7 \cdot 8$ & 73.9 & $11 \cdot 2$ & 77.4 & 9.5 & $70 \cdot 4$ & 9.9 & & & & & \\
\hline \multicolumn{14}{|c|}{$\begin{array}{l}\text { Percentage of time spent in light-intensity } \\
\text { physical activity }\end{array}$} \\
\hline Baseline & $21 \cdot 0$ & $8 \cdot 7$ & 24.8 & 8.7 & 22.9 & 9.6 & $22 \cdot 1$ & $12 \cdot 3$ & $-2 \cdot 8$ & $-7 \cdot 3,1 \cdot 8$ & $-5 \cdot 3$ & $-9.9,-0.7$ & 0.670 \\
\hline Endpoint & $25 \cdot 0$ & $7 \cdot 7$ & $25 \cdot 2$ & $10 \cdot 8$ & $21 \cdot 8$ & $9 \cdot 3$ & $28 \cdot 2$ & $9 \cdot 1$ & & & & & \\
\hline \multicolumn{14}{|c|}{$\begin{array}{l}\text { Percentage of time spent in } \\
\text { moderate-intensity physical activity }\end{array}$} \\
\hline Baseline & 0.61 & 0.53 & 0.61 & 0.57 & 0.58 & 0.65 & 0.71 & 0.56 & -0.2 & $-0.5,0.07$ & -0.4 & $-0.7,-0.1$ & 0.069 \\
\hline Endpoint & 0.53 & 0.51 & 0.39 & 0.40 & 0.47 & 0.31 & 0.77 & 0.62 & & & & & \\
\hline \multicolumn{14}{|c|}{$\begin{array}{l}\text { Percentage of time spent in } \\
\text { vigorous-intensity physical activity }\end{array}$} \\
\hline Baseline & 0.44 & 0.31 & 0.56 & 0.54 & 0.42 & 0.36 & 0.53 & 0.44 & -0.1 & $-0.5,0.2$ & -0.3 & $-0.6,0.1$ & $0.794 \dagger$ \\
\hline Endpoint & 0.56 & 0.49 & 0.51 & 0.59 & 0.38 & 0.32 & 0.68 & 0.75 & & & & & \\
\hline \multicolumn{14}{|c|}{ After-break class time (11.01-12.00 hours) } \\
\hline \multicolumn{14}{|c|}{ Physical activity (counts/min) } \\
\hline Baseline & $193 \cdot 2$ & $150 \cdot 2$ & $214 \cdot 1$ & $164 \cdot 6$ & 189.4 & $105 \cdot 7$ & $166 \cdot 4$ & $109 \cdot 7$ & -13.5 & $-90 \cdot 7,63.7$ & -50.5 & $-127 \cdot 8,26 \cdot 9$ & 0.395 \\
\hline Endpoint & 365.4 & 124.8 & 319.6 & 155.8 & 341.4 & 118.5 & 352.9 & 168.2 & & & & & \\
\hline \multicolumn{14}{|c|}{$\begin{array}{l}\text { Percentage of time spent in sedentary } \\
\text { physical activity }\end{array}$} \\
\hline Baseline & $66 \cdot 7$ & 14.9 & 73.0 & 11.4 & $70 \cdot 1$ & $12 \cdot 7$ & 73.0 & $12 \cdot 8$ & $1 \cdot 3$ & $-3 \cdot 5,6 \cdot 2$ & $5 \cdot 8$ & $0.9,10.7$ & 0.220 \\
\hline Endpoint & $59 \cdot 3$ & 8.45 & 62.5 & 9.58 & $60 \cdot 7$ & $6 \cdot 61$ & $58 \cdot 7$ & 8.58 & & & & & \\
\hline \multicolumn{14}{|c|}{$\begin{array}{l}\text { Percentage of time spent in light-intensity } \\
\text { physical activity }\end{array}$} \\
\hline Baseline & $24 \cdot 1$ & $9 \cdot 80$ & 30.5 & $12 \cdot 7$ & $27 \cdot 2$ & 11.6 & 24.8 & $12 \cdot 1$ & $-1 \cdot 1$ & $-5.5,3.4$ & -5.3 & $-9.7,-0.8$ & 0.280 \\
\hline Endpoint & 35.4 & 7.93 & $32 \cdot 7$ & 8.64 & 34.3. & 5.85 & $36 \cdot 6$ & 7.63 & & & & & \\
\hline \multicolumn{14}{|c|}{$\begin{array}{l}\text { Percentage of time spent in } \\
\text { moderate-intensity physical activity }\end{array}$} \\
\hline Baseline & 1.29 & 1.61 & 1.58 & 1.88 & 1.49 & $1 \cdot 19$ & $1 \cdot 11$ & 0.85 & 0.16 & $-0.8,1.1$ & 0.3 & $-0.6,1.2$ & $0.848 \dagger$ \\
\hline Endpoint & 2.51 & 1.69 & 2.58 & 1.86 & 2.50 & 1.60 & $2 \cdot 10$ & 1.34 & & & & & \\
\hline \multicolumn{14}{|c|}{$\begin{array}{l}\text { Percentage of time spent in } \\
\text { vigorous-intensity physical activity }\end{array}$} \\
\hline Baseline & 1.31 & 1.64 & 1.20 & 1.36 & 1.29 & 1.26 & 1.05 & 1.44 & -0.3 & $-1.4,0.9$ & -0.7 & $-1.8,0.5$ & $0.405 \dagger$ \\
\hline Endpoint & 2.76 & 1.65 & $2 \cdot 20$ & 2.04 & 2.46 & 1.50 & $2 \cdot 61$ & 2.79 & & & & & \\
\hline
\end{tabular}

* Intervention effects were estimated by using ANCOVA, adjusted for the respective baseline values, sex and age.

† Sex was a significant predictor $(P<0.05)$. 
during class time as done in the present study. Nonetheless, the authors speculated that children with a higher intake of $n$-3 long-chain-PUFA may be calmer and thus spend less time on physical activities of light intensity. A similar observation was made in a randomised controlled trial in healthy UK school children, which found that children supplemented with 400 and $1000 \mathrm{mg}$ DHA/d for 8 weeks showed a greater improvement in the ratings of 'relaxation' compared with controls, assessed by an Internet battery including visual analogue mood scales ${ }^{(18)}$.

In rural South African primary schools, children in classrooms are mainly required to sit and listen to teacher-directed instructions. Thus, it was no surprise that the children in the present study spent on average $75 \%$ of the morning class time in sedentary physical activity. The after-break class time, which was shorter than the morning class time, was characterised by higher activity, particularly higher percentages of time spent in moderate- and vigorous-intensity physical activities, and a higher variability in activity compared with the morning class time. We also observed that unconventional or out-of-class activities were performed more often during this time period. Thus, confirming our a priori assumption that the morning class time is more academically focused than the after-break class time. It is also possible that the school meal provided during break time affected physical activity during after-break class time. Furthermore, a study by Koch et $a l .{ }^{(35)}$ has shown that the percentage of primary school children who get up from their chair and spontaneously move increases from the beginning to the end of each school day.

Physical activity counts and intensity levels during after-break class time, particularly moderate- and vigorous-intensity physical activities, increased from baseline to endpoint in all the four groups. The endpoint assessment was conducted at the end of the school year, and it is likely that the teachers kept the children busy with self-study and play at the end of a school day in order to cope with a high burden of administrative work and exam preparations (information from personal communication with the teachers). This and the higher withingroup variability in activity during after-break class time might explain why the effects of DHA + EPA supplementation on after-break class time were only apparent for physical activity intensity levels and why after-break class time activity was not associated with the teacher ratings of behaviour.

Even though DHA + EPA supplementation did not have an effect on teacher rating scores at endpoint, lower levels of physical activity during morning class time was associated with lower levels of teacher-rated hyperactivity and oppositional behaviour at endpoint. Thus, it can be speculated that the lowering effect of DHA + EPA supplementation on physical activity during morning class time may indicate an improvement in ADHD-related behaviour, such as hyperactivity, in the present sample of non-ADHD-diagnosed school children. This would be in agreement with a recent randomised controlled trial conducted in healthy UK school children who underperformed in reading, showing that DHA supplementation reduced parent-rated ADHD-related symptoms (oppositional behaviour, hyperactivity and ADHD Index), assessed by using the Conners' Parent Rating Scales ${ }^{(15)}$. 


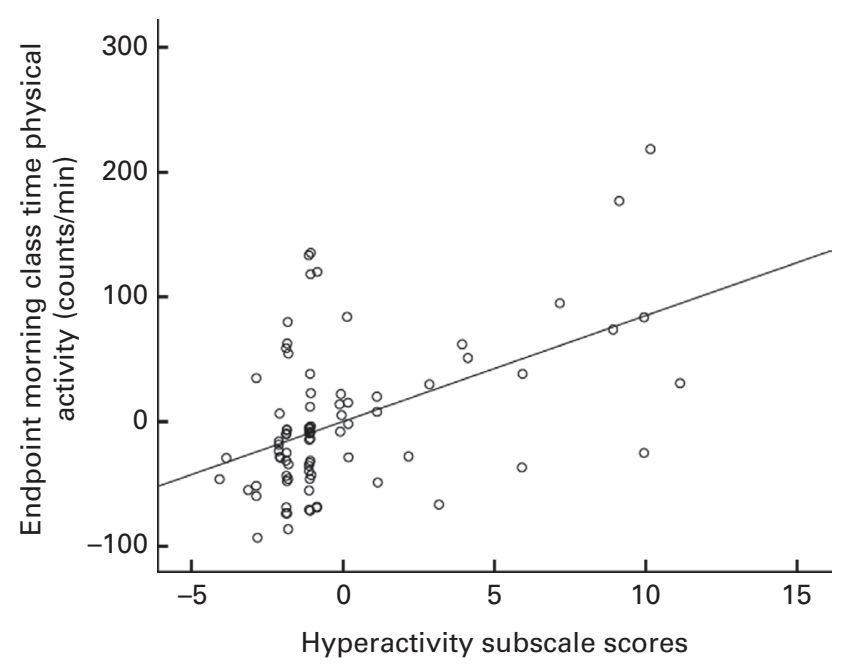

Fig. 1. Relationship between physical activity counts per min during morning class time and hyperactivity subscale scores of the Conners' Teacher Rating Scales - Revised: Short Form at endpoint after supplementation with iron and a mixture of DHA and EPA, alone or in combination, for 8.5 months. Variables on both axes were adjusted for age and sex. $r 0.472, P<0.001$, $n 85$.

However, the authors did not find an effect on teacher-rated behaviour. Although in the present study, the Conners' Teacher Rating Scales was not used to diagnose ADHD, it has been recommended that both parent and teacher rating scales be used to reliably assess ADHD-related symptoms ${ }^{(41)}$. We did not include parent questionnaires due to the local circumstances. Furthermore, we only collected Conners' Teacher Rating Scales data at endpoint because the teachers felt that they did not know their learners well enough to rate their behaviour at baseline (beginning of the school year). These are the limitations of the present study, considering that at least two intervention studies examining the effects of $n-3$ FA supplementation in children with ADHD have shown improved behaviour only on parent-rated behaviour ${ }^{(42-44)}$.

In comparison to class time, break time was the time period of voluntary physical activity and was characterised by higher physical intensity levels (predominantly light-intensity physical activity). Physical activity during break time was significantly higher at baseline than at endpoint in all the four groups, which might be explained by seasonal changes. Ridgers et al. ${ }^{(45)}$ investigated day-to-day and seasonal variability of physical activity during school breaks in nineteen school children aged 6-11 years and found a trend for physical activity levels to be higher in winter than in summer. Similarly, the present study found break time activity to be higher during the cooler autumn (baseline) than during spring (endpoint). It can also be speculated that the general decrease in activity levels during break time from baseline to endpoint was a factor that contributed to the increase in activity during after-break class time, as the children did not get rid of their excess energy during break time.

At baseline, higher $\mathrm{Hb}$ concentrations and better Fe status (based on TfR and ZnPP concentrations) were associated with higher voluntary physical activity during break time. This is in agreement with several human (mostly infant) and animal studies showing that ID and ID anaemia are associated with reduced motor activity ${ }^{(26-30)}$. The majority of these observational studies have been performed in infants, and to our knowledge, this is the first randomised controlled trial to investigate the effects of $\mathrm{Fe}$ supplementation on physical activity in school children. However, we were not able to show an increase in voluntary physical activity during break time with Fe supplementation. The only time during which voluntary or free-living activity was measured in the present study was during the $30 \mathrm{~min}$ break time. During this time period, children were also provided with a school meal and were administered the DHA + EPA or respective placebo capsules. Thus, extending the recording time of activity beyond school time could have provided a more comprehensive assessment of voluntary activity. Furthermore, the prevalence of ID anaemia in the children studied was low (8.5\%) and the majority of children were only moderately Fe-deficient. Thus, it can be speculated that an effect of Fe supplementation to increase physical activity during break time would have been more likely in severely ID and ID anaemia children. We also found no effect of Fe supplementation on physical activity during class time and ADHD-related behaviour. Only one small study by Konofal et $a l^{(14)}$ has investigated the effects of Fe supplementation on ADHD-related symptoms in Fe-deficient, non-anaemic (serum ferritin $<30 \mu \mathrm{g} / \mathrm{l}$ ) children diagnosed with ADHD, and only found trends towards improved parent-rated and teacher-rated behaviour.

While the validity and reliability of the Actical accelerometer for the assessment of physical activity in children has been demonstrated previously ${ }^{(34,36,37)}$, the validity for the use of the accelerometer as a tool to assess ADHD-related behaviour, particularly during class time, has not yet been established. Increased physical activity during class time may reflect on behaviour, such as restlessness, squirming and inability to remain still - all of which are ADHD-related behaviour. Therefore, our finding that higher physical activity during class time was associated with higher teacher-rated oppositional, hyperactivity and ADHD Index scores suggests that the accelerometer might be a useful tool to assess ADHD-related behaviour in school children. Unlike the Conners' Teacher Rating Scales, which is based on observation, the accelerometer is able to provide a tangible and unbiased measure of physical activity that might be related to behaviour.

The strengths of the present study were that all children attended the same school and, thus, the physical environment was the same for all of them. Even though it was not possible for us to observe the participating children in the classroom, the researcher responsible for executing the activity measurements was present at school on the days of data collection, which made it possible to pick up extraordinary events/activities (e.g. accident happening on the school ground and sports day), which could have confounded the data. The limitations of the present study were the lack of baseline teacher-rated behaviour, the lack of parent-rated behaviour, and the restriction of physical activity measurements to school time. Furthermore, splitting up the class-time physical activity data into morning class time and after-break class time resulted in 
more endpoints tested, and therefore it might have increased the chance for false-positive outcomes.

In conclusion, the present study provides evidence that DHA + EPA supplementation might decrease physical activity levels during class time, and that lower activity levels at endpoint were associated with lower levels of teacher-rated hyperactivity and oppositional behaviour in Fe-deficient, non-ADHD-diagnosed South African school children. To our knowledge, the present study is the first to use the accelerometer to detect ADHD-related behaviour in a classroom set-up in children without diagnosed behavioural disorders. Our findings provide further evidence for a potential relationship between Fe status and voluntary physical activity. However, in contrast to our hypothesis, Fe supplementation did not affect physical activity. The results of the present study further indicate that the accelerometer might be a sensitive tool to assess the potential effects of a nutrition intervention on motor activity and ADHD-related behaviour in school children, and its sensitivity and specificity for this purpose deserves further investigation in future trials.

\section{Supplementary material}

To view supplementary material for this article, please visit http://dx.doi.org/10.1017/S0007114514003493

\section{Acknowledgements}

The authors thank the fieldworkers, the teachers and the principal of the school for their support, the children and parents for their participation in the trial, MRC and NWU colleagues, especially Ellenor Rossouw, and students for their assistance during the field and laboratory work.

The present study was financially supported by Unilever Research and Development (Vlaardingen, The Netherlands), the North-West University (Potchefstroom, South Africa) and the Medicor Foundation (Vaduz, Principality of Liechtenstein). Paul Lohmann GmbH (Lomapharm, Emmertal, Germany) provided the Fe supplements and Burgerstein AG (Rapperswil, Switzerland) provided the DHA + EPA capsules. The European-South African Partnership in Nutrition Research provided travel support.

The authors' responsibilities were as follows: C. M. S., M. B. Z., J. B. and J. K. designed the study; J. G., J. B. and C. M. S. conducted the study; J. B. analysed the biochemical indicators; J. B. and J. G. performed the statistical analyses; C. M. S., J. B. and J. G. wrote the first draft of the manuscript; J. B. had the responsibility for the final content of the paper and the decision to submit for publication. All authors read and edited the manuscript, and were involved in the interpretation of the results and had full access to all the data.

J. B. and C. M. S. received speaking honoraria from Unilever. The rest of the authors have no conflict of interest.

\section{References}

1. Schuchardt JP, Huss M, Stauss-Grabo M, et al. (2010) Significance of long-chain polyunsaturated fatty acids (PUFAs) for 
the development and behaviour of children. Eur J Pediatr 169, 149-164.

2. Lozoff B (2011) Early iron deficiency has brain and behavior effects consistent with dopaminergic dysfunction. $J$ Nutr 141, 740S-746S

3. Cortese S, Angriman M, Lecendreux M, et al. (2012) Iron and attention deficit/hyperactivity disorder: what is the empirical evidence so far? A systematic review of the literature. Expert Rev Neurother 12, 1227-1240.

4. Chen MH, Su TP, Chen YS, et al. (2013) Association between psychiatric disorders and iron deficiency anemia among children and adolescents: a nationwide population-based study. BMC Psychiatry 13, 161.

5. Gow RV \& Hibbeln JR (2014) Omega-3 and treatment implications in Attention Deficit Hyperactivity Disorder (ADHD) and associated behavioral symptoms. Lipid Technol 26, $7-10$.

6. Salem N Jr, Moriguchi T, Greiner RS, et al. (2001) Alterations in brain function after loss of docosahexaenoate due to dietary restriction of $n-3$ fatty acids. J Mol Neurosci 16, 299-307 (discussion 317-321).

7. Beard J (2003) Iron deficiency alters brain development and functioning. J Nutr 133, 1468S-1472S.

8. Anjos T, Altmae S, Emmett P, et al. (2013) Nutrition and neurodevelopment in children: focus on NUTRIMENTHE project. Eur J Nutr 52, 1825-1842.

9. Baumgartner J, Smuts CM, Malan L, et al. (2012) Combined deficiency of iron and ( $n-3)$ fatty acids in male rats disrupts brain monoamine metabolism and produces greater memory deficits than iron deficiency or ( $n$-3) fatty acid deficiency alone. J Nutr 142, 1463-1471.

10. Transler C, Mitchell S \& Eilander A (2013) Could polyunsaturated fatty acids deficiency explain some dysfunctions found in ADHD? Hypotheses from animal research. J Atten Disord 17, 20-28.

11. McNamara RK \& Strawn JR (2013) Role of long-chain omega-3 fatty acids in psychiatric practice. PharmaNutrition 1, $41-49$.

12. Transler C, Eilander A, Mitchell S, et al. (2010) The impact of polyunsaturated fatty acids in reducing child attention deficit and hyperactivity disorders. J Atten Disord 14, 232-246.

13. Richardson AJ \& Montgomery P (2005) The Oxford-Durham study: a randomized, controlled trial of dietary supplementation with fatty acids in children with developmental coordination disorder. Pediatrics 115, 1360-1366.

14. Konofal E, Lecendreux M, Deron J, et al. (2008) Effects of iron supplementation on attention deficit hyperactivity disorder in children. Pediatr Neurol 38, 20-26.

15. Richardson AJ, Burton JR, Sewell RP, et al. (2012) Docosahexaenoic acid for reading, cognition and behavior in children aged 7-9 years: a randomized, controlled trial (the DOLAB Study). PLOS ONE 7, e43909.

16. Itomura M, Hamazaki K, Sawazaki S, et al. (2005) The effect of fish oil on physical aggression in schoolchildren - a randomized, double-blind, placebo-controlled trial. J Nutr Biochem 16, 163-171.

17. Hamazaki K, Syafruddin D, Tunru IS, et al. (2008) The effects of docosahexaenoic acid-rich fish oil on behavior, school attendance rate and malaria infection in school children a double-blind, randomized, placebo-controlled trial in Lampung, Indonesia. Asia Pac J Clin Nutr 17, 258-263.

18. Kennedy DO, Jackson PA, Elliott JM, et al. (2009) Cognitive and mood effects of 8 weeks' supplementation with $400 \mathrm{mg}$ or $1000 \mathrm{mg}$ of the omega-3 essential fatty acid docosahexaenoic acid (DHA) in healthy children aged 10-12 years. Nutr Neurosci 12, 48-56.
19. Kirby A, Woodward A, Jackson S, et al. (2010) A doubleblind, placebo-controlled study investigating the effects of omega-3 supplementation in children aged 8-10 years from a mainstream school population. Res Dev Disabil 31, $718-730$.

20. McNamara RK, Able J, Jandacek R, et al. (2010) Docosahexaenoic acid supplementation increases prefrontal cortex activation during sustained attention in healthy boys: a placebo-controlled, dose-ranging, functional magnetic resonance imaging study. Am J Clin Nutr 91, 1060-1067.

21. Sonuga-Barke EJ \& Rubia K (2008) Inattentive/overactive children with histories of profound institutional deprivation compared with standard ADHD cases: a brief report. Child Care Health Dev 34, 596-602.

22. Levant B, Ozias MK, Davis PF, et al. (2008) Decreased brain docosahexaenoic acid content produces neurobiological effects associated with depression: interactions with reproductive status in female rats. Psychoneuroendocrinology 33, 1279-1292.

23. Levant B, Zarcone TJ \& Fowler SC (2010) Developmental effects of dietary $n-3$ fatty acids on activity and response to novelty. Physiol Behav 101, 176-183.

24. Hauser J, Makulska-Gertruda E, Reissmann A, et al. (2014) The effects of nutritional polyunsaturated fatty acids on locomotor activity in spontaneously hypertensive rats. Atten Defic Hyperact Disord 6, 61-65.

25. Damsgaard CT, Stark KD, Hjorth MF, et al. (2013) n-3 PUFA status in school children is associated with beneficial lipid profile, reduced physical activity and increased blood pressure in boys. Br J Nutr 110, 1304-1312.

26. Lozoff B, Klein NK, Nelson EC, et al. (1998) Behavior of infants with iron-deficiency anemia. Child Dev 69, 24-36.

27. Pinero D, Jones B \& Beard J (2001) Variations in dietary iron alter behavior in developing rats. J Nutr 131, 311-318.

28. Angulo-Kinzler RM, Peirano P, Lin E, et al. (2002) Twentyfour-hour motor activity in human infants with and without iron deficiency anemia. Early Hum Dev 70, 85-101.

29. Angulo-Kinzler RM, Peirano P, Lin E, et al. (2002) Spontaneous motor activity in human infants with iron-deficiency anemia. Early Hum Dev 66, 67-79.

30. Golub MS, Hogrefe CE, Germann SL, et al. (2006) Behavioral consequences of developmental iron deficiency in infant rhesus monkeys. Neurotoxicol Teratol 28, 3-17.

31. Harahap H, Jahari AB, Husaini MA, et al. (2000) Effects of an energy and micronutrient supplement on iron deficiency anemia, physical activity and motor and mental development in undernourished children in Indonesia. Eur J Clin Nutr 54, Suppl. 2, S114-S119.

32. Angulo-Barroso RM, Peirano P, Algarin C, et al. (2013) Motor activity and intra-individual variability according to sleepwake states in preschool-aged children with iron-deficiency anemia in infancy. Early Hum Dev 89, 1025-1031.

33. Baumgartner J, Smuts CM, Malan L, et al. (2012) Effects of iron and $n-3$ fatty acid supplementation, alone and in combination, on cognition in school children: a randomized, double-blind, placebo-controlled intervention in South Africa. Am J Clin Nutr 96, 1327-1338.

34. Rosenkranz RR, Rosenkranz SK \& Weber C (2011) Validity of the Actical accelerometer step-count function in children. Pediatr Exerc Sci 23, 355-365.

35. Koch P, Montagner H \& Soussignan R (1987) Variation of behavioral and physiological variables in children attending kindergarten and primary school. Chronobiol Int $\mathbf{4}$, 525-535. 
36. Evenson KR, Catellier DJ, Gill K, et al. (2008) Calibration of two objective measures of physical activity for children. J Sports Sci 26, 1557-1565.

37. Colley RC \& Tremblay MS (2011) Moderate and vigorous physical activity intensity cut-points for the Actical accelerometer. J Sports Sci 29, 783-789.

38. Epstein JN, March JS, Conners CK, et al. (1998) Racial differences on the Conners Teacher Rating Scale. J Abnorm Child Psychol 26, 109-118.

39. Conners CK, Sitarenios G, Parker JD, et al. (1998) Revision and restandardization of the Conners Teacher Rating Scale (CTRS-R): factor structure, reliability, and criterion validity. J Abnorm Child Psychol 26, 279-291.

40. American Psychiatric Association (2000) Diagnostic and Statistical Manual of Mental Disorders: DSM-IV-TR, 4th ed., text revision Washington, DC: American Psychiatric Association.

41. Pelham WE Jr, Fabiano GA \& Massetti GM (2005) Evidencebased assessment of attention deficit hyperactivity disorder in children and adolescents. I Clin Child Adolesc Psychol 34, 449-476.

42. Sinn N \& Bryan J (2007) Effect of supplementation with polyunsaturated fatty acids and micronutrients on learning and behavior problems associated with child ADHD. J Dev Behav Pediatr 28, 82-91.

43. Belanger SA, Vanasse M, Spahis S, et al. (2009) Omega-3 fatty acid treatment of children with attention-deficit hyperactivity disorder: a randomized, double-blind, placebo-controlled study. Paediatr Child Health 14, 89-98.

44. Johnson M, Ostlund S, Fransson G, et al. (2009) Omega-3/ omega- 6 fatty acids for attention deficit hyperactivity disorder: a randomized placebo-controlled trial in children and adolescents. J Atten Disord 12, 394-401.

45. Ridgers ND, Stratton G, Clark E, et al. (2006) Day-to-day and seasonal variability of physical activity during school recess. Prev Med 42, 372-374

46. Cook JD, Flowers CH \& Skikne BS (2003) The quantitative assessment of body iron. Blood 101, 3359-3364. 